\title{
The Research of 3D Modeling between Visual \& Creativity
}

\author{
Dahlan Abdul Ghani, Muhammad Naim Bin Supian, Luqman Zulhilmi Bin Abdul 'Alim
}

\begin{abstract}
The 3-Dimensional method are grown rapidly and the technology to generate an animation in $3 D$ also having a series of evolved rapidly where Western animation industries pioneered this animation method. $3 D$ animation become a method to producing an animation. In creative multimedia industries, Character modeling are the most important step to make an animation. Character modelling are in Pre-Production process which the animator and the character designers will modeling the character in 3-Dimensional method. This paper will discuss about the method are using in $3 D$ modeling and parts of the whole process of modeling in 3D. This paper also will discuss about the pipeline of modeling a character in 3D. The whole process into $3 D$ modeling, UV mapping, and model texturing. Modeling the human from the basic shape until form a human shape and form. This paper also will discuss about the development of $3 D$ modeling in Malaysia refers to the famous animation film in Malaysia.
\end{abstract}

Keyword: 3-Dimensional,UV Mapping,Model Texturing, pipeline, Pre-Production

\section{INTRODUCTION}

\subsection{What is 3 Dimensional (3D)}

3 Dimensional also known as 3D is a process to developing a mathematical representation to converting an image from 2 Dimensional images using a specific software. $3 \mathrm{D}$ modelling is process of creating a $3 \mathrm{D}$ object using $3 \mathrm{D}$ modelling programs. Back in history, 3D modelling is used in engineering sectors and manufacturing sectors. Multimedia and animation use this technique to modeling a character to animate and for film studies proposes. According to (Bailey, April 15, 2013), Characters, whether in books, movies, or video games, are one of the most important factors to consider when trying to create media that people can connect to. The 3D imaginary are used in many sectors. According to (Bane, 2012), 3D also using in medicine practices to define a source of problem. Art has been a part of the medical industry since the beginning of modern medical practices. Medical practices using 3D imaginary method to ease and to improve the productivities among medical practices. In Architecture sectors, the 3D imaginary are used widely in this sectors. According to (Bane, 2012) Architects use 3D software in conjunction with CAD programs not only to create models, but to test and

Revised Manuscript Received on September 10, 2019.

Dahlan Abdul Ghani, Universiti Kuala Lumpur (UniKL), Malaysian Institute of Information Technology, 1016, Jalan Sultan Ismail, 50250 Kuala Lumpur, Malaysia.

(E-mail: dahlan@unikl.edu.my)

Muhammad Naim Bin Supian, Universiti Kuala Lumpur (UniKL), Malaysian Institute of Information Technology, 1016, Jalan Sultan Ismail, 50250 Kuala Lumpur, Malaysia.

(E-mail: naimsupian94@gmail.com)

Luqman Zulhilmi Bin Abdul 'Alim, Limkokwing University, Inovasi 1-1, Jalan Teknokrat 1/1-63000, Cyberjaya, Malaysia

(E-mail: luqmanzulhilmi999@yahoo.com) visualize those models to see what structures would look like photo realistically before they are actually created. Realistic modeling of the human body in 3D has many applications ranging from fashion to the production of movies and video games. 3D imaginary also used in robotic sectors. According to (Xi-Dao LUAN, 2008) In the past, the main applications of $3 \mathrm{D}$ modeling were visual inspection and robot guidance. Nowadays, the emphasis is shifting. 3D modeling has been widely used in areas including computer graphics, virtual reality and communication, and there is more and more demand for 3D content for tissue engineering and heritage protection. In different fields of research and applications, 3D modeling methods of modeldata acquisition and modeling have their own specialty. The uses of 3D imaginary is spread widely and it's still develop until now. The used of 3D imaginary is in Animation, Creative Multimedia industries, Engineering sectors and Medical industries.

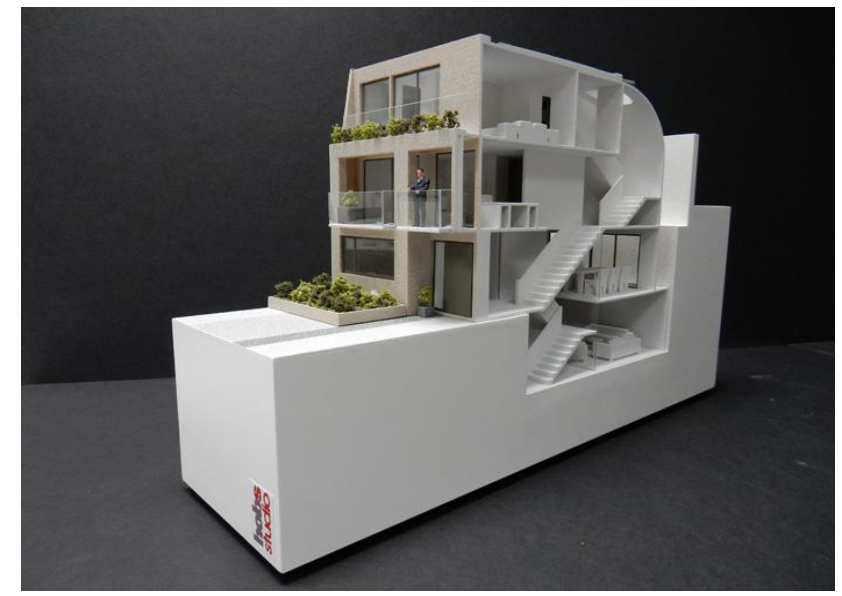

Pictures 1.1 Modeling in Architecture sectors Source: AEC magazine

3D started to exist through Computer Generated Imagery (CGI) which is the main source of digital visualization. Most animation studios took the role in developing 3D content. Some of them giving the access to other companies to invest on the production of advanced 3D production software. According to (Weh-Cheih Chang, 2015) For 3D modeling, the designer would appreciate the idea if the automated tool can assist in the process by offering the capability of both the 3D scene together with the animated characters to attain the best possible effects. The designer must combine the best capabilities to create the special effect for the character to increase the 'mood' for the character.

Published By:

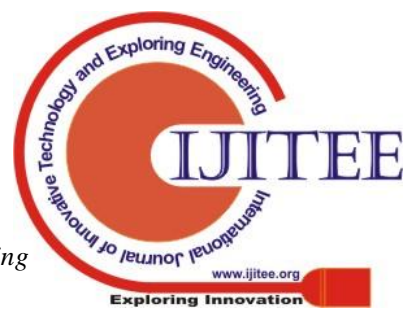




\subsection{D Modeling in Creative Multimedia sectors.}

According to (Wise R, 2000) multimedia has transformed from individual media to a combination of text, images, sounds and video with the introduction of electronic technology. Inside multimedia domain, the sectors are split into few parts, department and production. Creative commercials goals to motion film are made for television and theater. This are for creating and developing a new method in multimedia industries. From years, creative multimedia are evolving and facing some revolution creating a different method in delivering a creative idea and message. These industry creating a very specific task in various parts needed in the production according to essential for a certain skills.

\subsection{D Modelling Category}

Digital modelling, also best known as 3D modelling, is the process of creating a mathematical presentation of a three-dimensional shape of an object. In other words, it means the construction of an object in the x-axis, y-axis and $\mathrm{z}$-axis dimensions of digital territory using 3D software. According to (Vaughan, 2012) Digital models can be broken down into three types: Polygonal models are made up of a collection of points, edges, and polygons, NURBS surfaces consist of a network of curves with smooth surfaces between them and the last types is Subdivision. For the 3D modeling in AutoCAD, there are 4 types of them, there are 3D wireframe. For 3D wireframe, it's very useful to references and modeling modification. The second types of 3D modeling is 3D Solid. For 3D solid, is to combining the primitive object and sectioning capabilities. The 3D Surface is for modelling in curved section and surface. It's also can manipulate and accurate. And the last types is 3D Mesh. The 3D Mesh is for sculpt and smoothing capabilities.

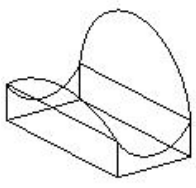

3D Wireframe

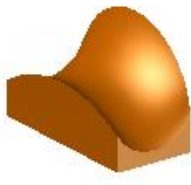

3D Solid

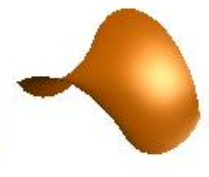

3D Surface

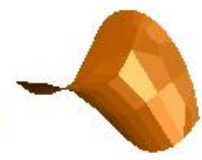

3D Mesh
Pictures 1.2 The types of 3D Modeling in AutoCAD Source: AutoDesk Knowledge Network

For modeling, there are types of 3D modeling such as wireframe, surface, and solid. Each type has its own creation and editing techniques.
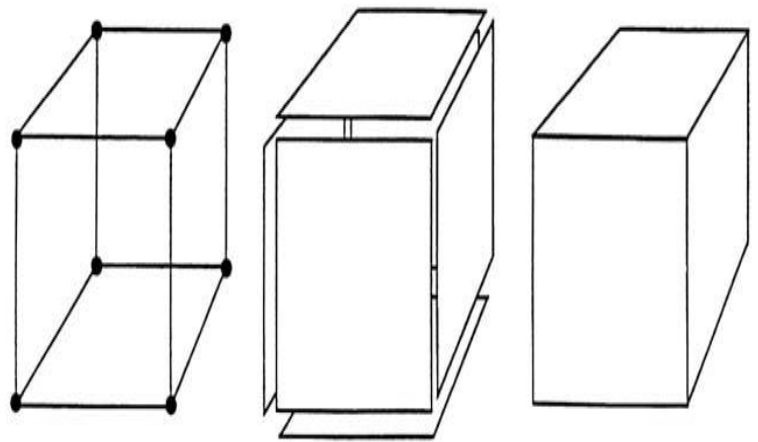

wireframe surface solid
Pictures 1.3 Types of 3D Modeling

Source: The National Academics Press

\subsection{Process and Work flow in 3D Character Modeling}

Modeling According to (Vaughan, 2012), There are the serval step that animator must follow before produce a 3D character modeling. There are Modeling, Texturing and Rigging, also known as setup. Modeling is a major process that 3D artist must follow. Modeling character is the form converting 2D drawing and schematic drawing to 3D form using serval application or software. Everything that needs to be seen onscreen or rapid-prototyped has to be modeled. A model is a geometric surface representation of an object that can be rotated and viewed in a 3D-animation software package. According to (Vaughan, 2012) Several comprehensive 3D animation software packages are used for modeling, animation, simulation, visual effects, and rendering. All of these packages are used in a wide range of industries: television, games, advertising, architectural rendering, medical simulation, publishing, and graphic design. There are many software and application that can translate the 2D sketches and drawing into 3D modeling such as Autodesk Maya, Autodesk 3ds, Blender. The 3D modeling artist also can digitally sculpt the $3 \mathrm{D}$ image to form a model. The software are use to this method is Pixcologic's ZBrush, and Autodesk Mudbox. In architecture industries, the software are used is Autodesk's AutoCAD, the Robert McNeel \& Associates Rhinoceros and Dassault Systemes SolidWorks products, and Google SketchUp Pro. After this method are applied, the texture artist will apply texturing process. The texturing artist will shading the model and the model will painted. The texturing process is applying colors and texture to model to give the realistic touch to model. This process also to make the model are match to the design to the concept. The next step to complete this stage is rigging and placement process. The rigging process is the process that putting the control rig into the geometry shape and creating the system to the modeling. According to (Bailey, April 15, 2013) Rigging is basically building a skeleton for a model that can then be used to move the model The rigging process is the most complicated process in developing a character modeling.. Modeling a character should be taking a long time to develop it because depends into what character to be develop. More complex the character design produce, its maybe taking a long time to design and convert it into 3D.

The method is using is Polygonal modeling. There are have Points in $3 \mathrm{D}$ space, are called vertices connected by line segments to form a polygon mesh. The vast majority of 3D models today are built as textured polygonal models, because they are flexible and because computers can render them so quickly. The second method is Curve modelling. Surfaces are defined by curves, which are influenced by weighted control points. The curve follows (but does not necessarily interpolate) the points. Increasing the weight for a point will pull the curve closer to that point. Curve types include nonuniform rational B-spline (NURBS), splines, patches, and geometric primitives and final process of $3 \mathrm{D}$ Modeling is Digital sculpting. Still a fairly new method of modeling, 3D sculpting has become very popular in the few 
years it has been around. There are currently three types of digital sculpting: Displacement, which is the most widely used among applications at this moment, uses a dense model (often generated by subdivision surfaces of a polygon control mesh) and stores new locations for the vertex positions through use of a 32bit image map that stores the adjusted locations. Volumetric, loosely based on voxels, has similar capabilities as displacement but does not suffer from polygon stretching when there are not enough polygons in a region to achieve a deformation. Dynamic tessellation is similar to voxel but divides the surface using triangulation to maintain a smooth surface and allow finer details. These methods allow for very artistic exploration as the model will have a new topology created over it once the models form and possibly details have been sculpted. The new mesh will usually have the original high-resolution mesh information transferred into displacement data or normal map data if for a game engine.

\subsection{Conclusion}

As a conclusion, the $3 \mathrm{D}$ character modeling has many pipelines and steps to follow to make sure that $3 \mathrm{D}$ character modeling can be produce. To making a character model in $3 \mathrm{D}$, there are types and many method to create a character. Many type of character modeling step can follow to make that character more realistic. Character modeling in Malaysia still in development stage which many types of modeling and method can be develop by Malaysian animators For realizing this, the animators in Malaysia must improve skills and technical skills in 3D Character modeling. Malaysian animators also can develop own method in 3D character modeling. The revolution of technology in 3D helps animators especially character designers in Malaysia to develop more character modeling in $3 \mathrm{D}$.

\section{RELATED WORK}

2.1 The Development of $3 D$ Character Modeling in Malaysia

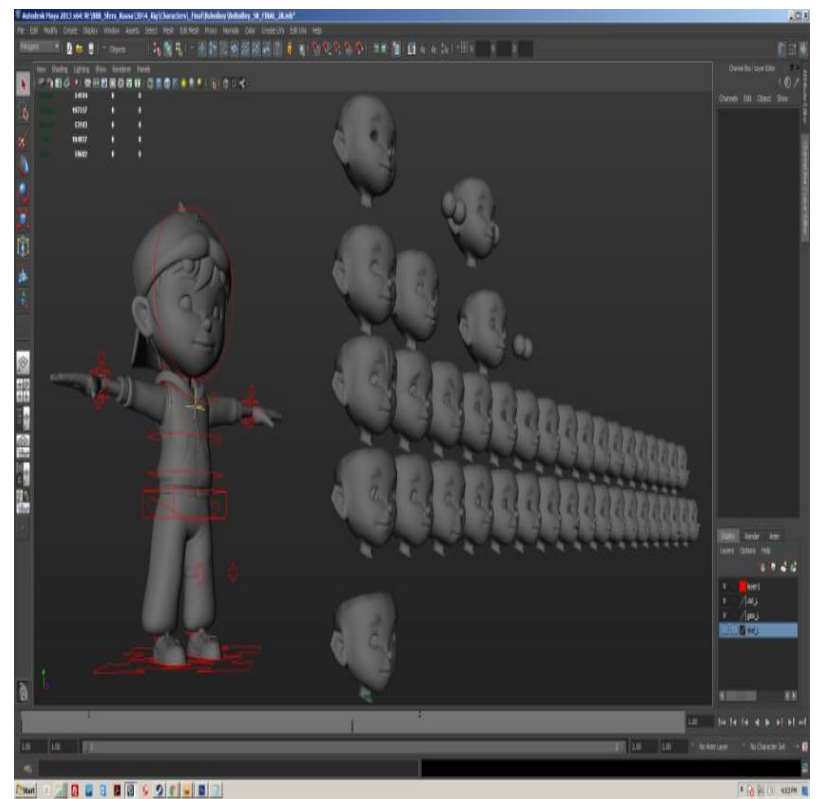

Picture 2.1

The layout of morpher of Boboiboy

Source: Veedo.my
3D modelling is one of method in creative multimedia are facing rapidly revolution including Malaysia creative industries. Les Copaque is the first 3D company for developing The first Malaysia 3D short animated series is Upin \& Ipin (2007) and les copaque continued with Malaysia first Malaysia 3D animation Film is Geng: Pengembaraan Bermula (2009) which this animation received a positive feedback. According to (Isa, 2012), there television series, Upin dan Ipin started to make a substantial impact in Malaysia animation scene in 2008, followed by their successful 3D animated film, Geng: the adventure begins in 2009. The total cost to produce the film was RM 4 Million, making it's the wone of the most expensive local film ever produce in Malaysia, but the cheapest 3D animation film produce in the world. After that, many animation company in Malaysia are start using the 3D animation method to making an animation. The 3D character modelling in Malaysia are trying to include the Malays element to make the animation are more suitable to adapt in Malaysia. After the success of the character Upin \& Ipin, many animation industries produce more character in 3D like Ali plays role in Agen Ali, Boboboy in Boboboy siries and Malaysia animation industries also produce an animal character in 3D like Sang Kancil in Pada Zaman Dahulu

In Malaysia, the 3D character modeling is considered as new if compare with $2 \mathrm{D}$ character modeling.

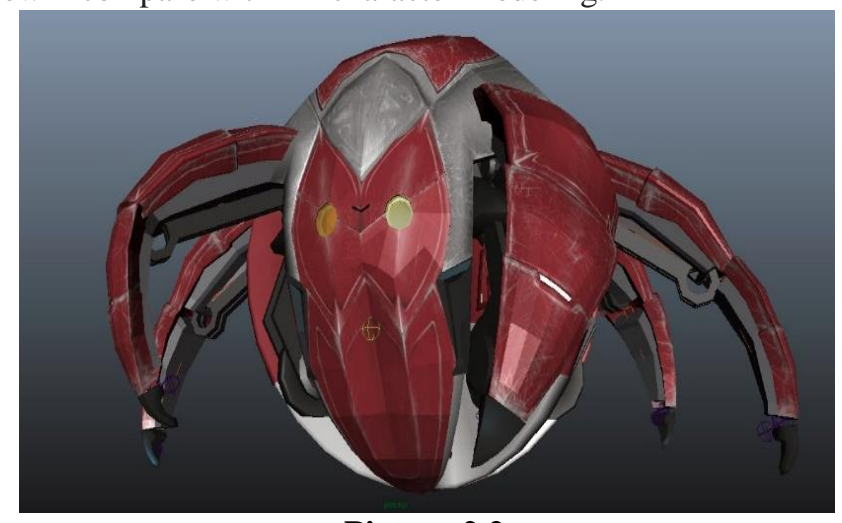

Picture 2.2

Model of giant $1^{\text {ST }}$ Generation Ochobot in AutoDesk Maya

Source : BoboiboyWiki

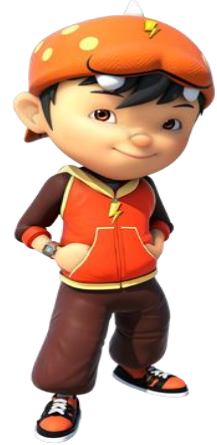

Pictures 2.3 Boboiboy modeling

Source : BoboiboyWiki 


\subsection{Concept and Sketches}

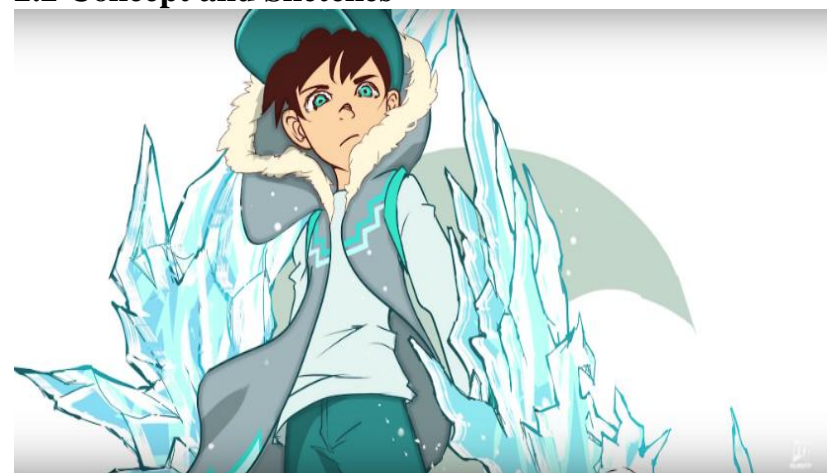

Pictures 2.4 The concept art of the Boboboy Ice. Source : YouTube, Monsta Channel

For this paper, I will review about a video 'Di Sebailk Tabir-Boboiboy The Movie'. This video are produce by Monsta, the animation studios are creating Boboiboy film.

Before crating a character, the concept idea and sketches must been produce by concept artist. According to (Plata, 2013) the main objective of reference is to start the operation of 3D concept design for the characters.. According to (Monsta, 2016) the concept idea must been produce before staring the animation.

\subsection{Modeling Step}

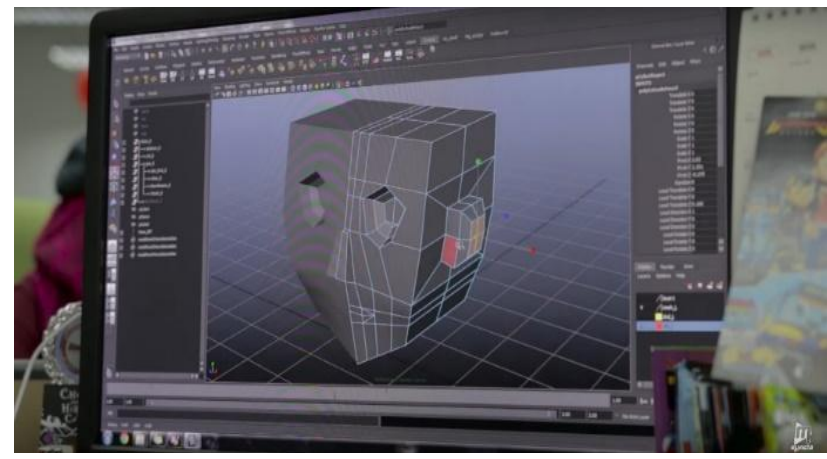

Pictures 2.5 Modeling from cube

\section{Source : YouTube, Monsta Channel}

For this step, the modeling starting from cube and the modeling design will take over by modeler. For the Boboboy the movie, the modeler using AutoDesk 3D Maya software to create the character. For this step, from the box, the modeler will design the character following the concept art. modeler using many setting in Maya Software to making the character as the concept art.

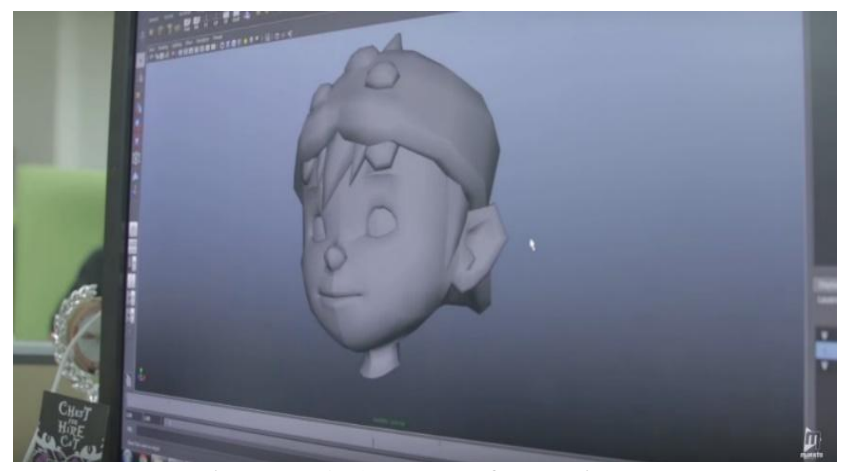

Pictures 2.6 Head of Boboiboy

Source : YouTube, Monsta Channel

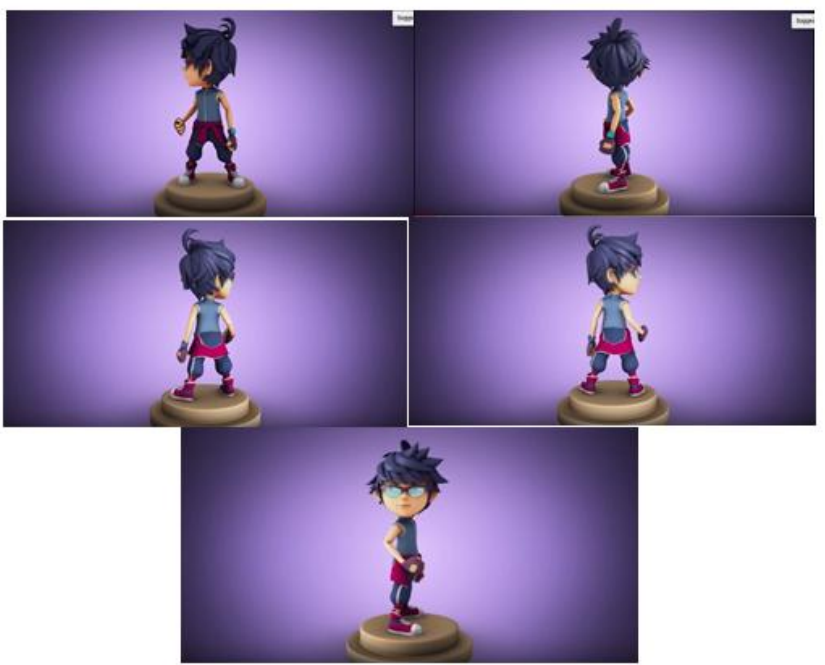

Pictures 2.7 Fang character turnaround Source: YouTube, Monsta Channel

\section{RESEARCH METHODOLOGY \& RESULTS}

\subsection{Character Design Model}

Character is a display of the weaknesses, strength, and the bad characteristic of a character. Character is the main factor for a film and animation. The character design also playing major role to adapt the storylines, and the mood for an animation film. However, undeniable to say, the character development, design and modeling still in low level. According to (Faryna Mohd Khalis, 2016) Malaysia is lacking a sense of identity in producing animation character design. Character design is the second most important criterion after the story lines. According to (Faryna Mohd Khalis, 2016) a character considered a success when it is believable to the audience even thought it's does not exist. The character must to be raw, unique and fresh. A stereotyped character or a weak identity usually fails to attract the audience. Characters are not necessarily human figures. They also be presented in other figures like animals, floras or object. The character like Boboiboy and Upin \& Ipin considered as successful character because the audience believed they are exist in real world. the character cannot be rigid into the human form, can be replace with object, food and animals.

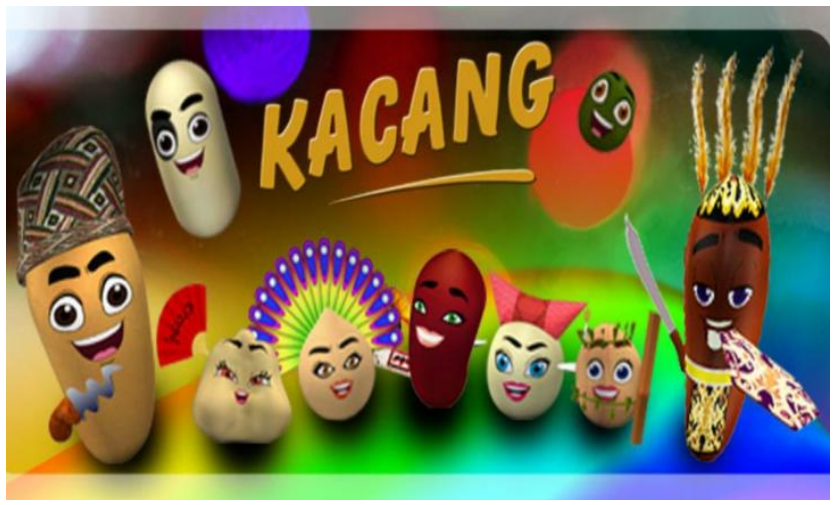

Figure 3.1 animation series, Kacang, using food as character in this animation 


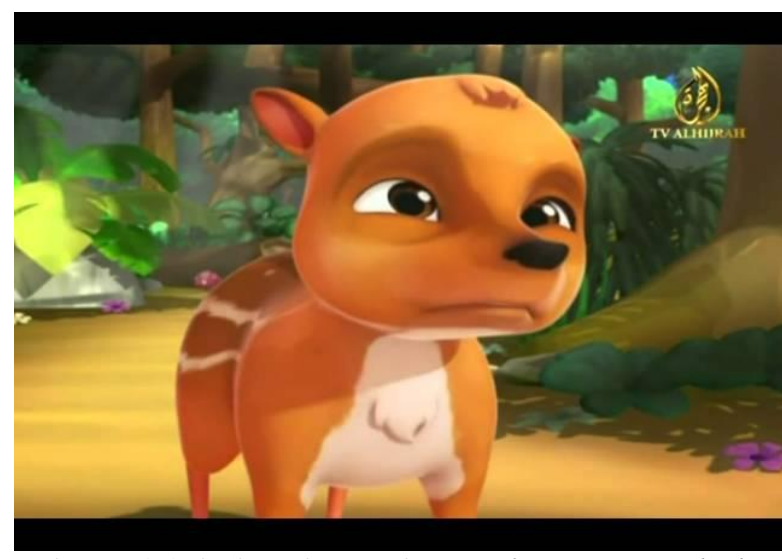

Figure 3.2 Animation series, Pada Zaman Dahulu, using animals as character

\subsection{Physical Requirement in $3 D$ Character Modeling}

According to Pixar, to create a good character design, there are must have Research and evaluate. It's very helpful to create a good character design. After that is the target audience and who to we want aimed. The visual impact also playing the good relationship to make a good animation. Exaggerated characteristic and color also playing the role. The color can help to communicate to the audience to more interested to follow the animation. Conveying personality the character. Trying to express ourself in the animation. Trying to set the goals and dreams to the character to making the character more realistic, its depending to the what character are we design.

$3 \mathrm{D}$ modelling is a progress which can be carried out by machines and softwares or 3D modellers for personalized production. Modeller main task is to model illustrations into 3D components which can be organics, architectures, or even environments.

\subsection{Malaysian Physical Character design}

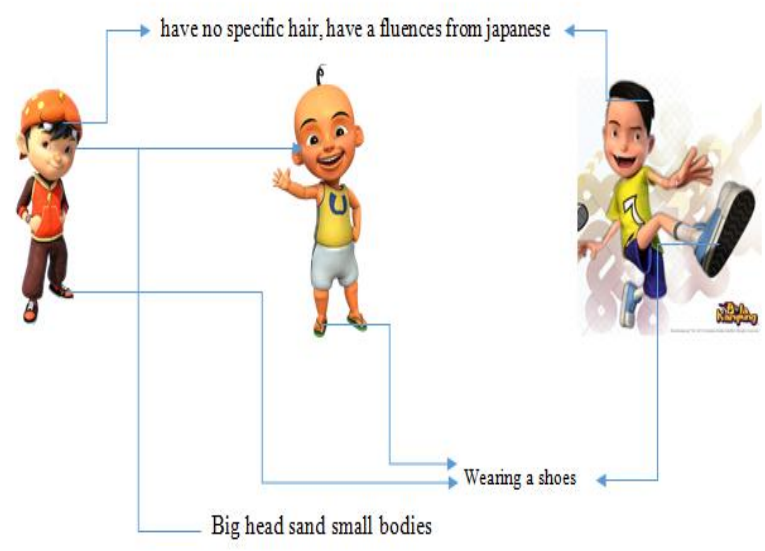

The malaysian 3D character have a influenses from japanese and western identity such as the facial shape, eye shape and the 'big-head styles'. However, the malaysian identity are also influnted this character such as Upin from Upin \& Ipin and iwan from Bola Kampung such as the outfit and the skin color tone. The bodyshape of the character also like asian look alike shape. According to (Ishak, 2014) All physical objects and non-physical attributes, identified as 'Malaysian' were retrieved from both the foregrounds and backgrounds of the animation series.
The boboiboy character receved a small influenses of Japaniese styles of animation. This is for making the boboiboy more heroitic and look more intersting. According to (Faryna Mohd Khalis, 2016) Boboiboy character has physical traits that are influenced by the Japanese (J) style especially the facial features and haircut. Boboiboy has Japanese animation characteristics with sharp and flat hair, medium-sized eyes, small nose, and thin lips

3.4 The model structure for developing a $3 D$ Character Modeling.

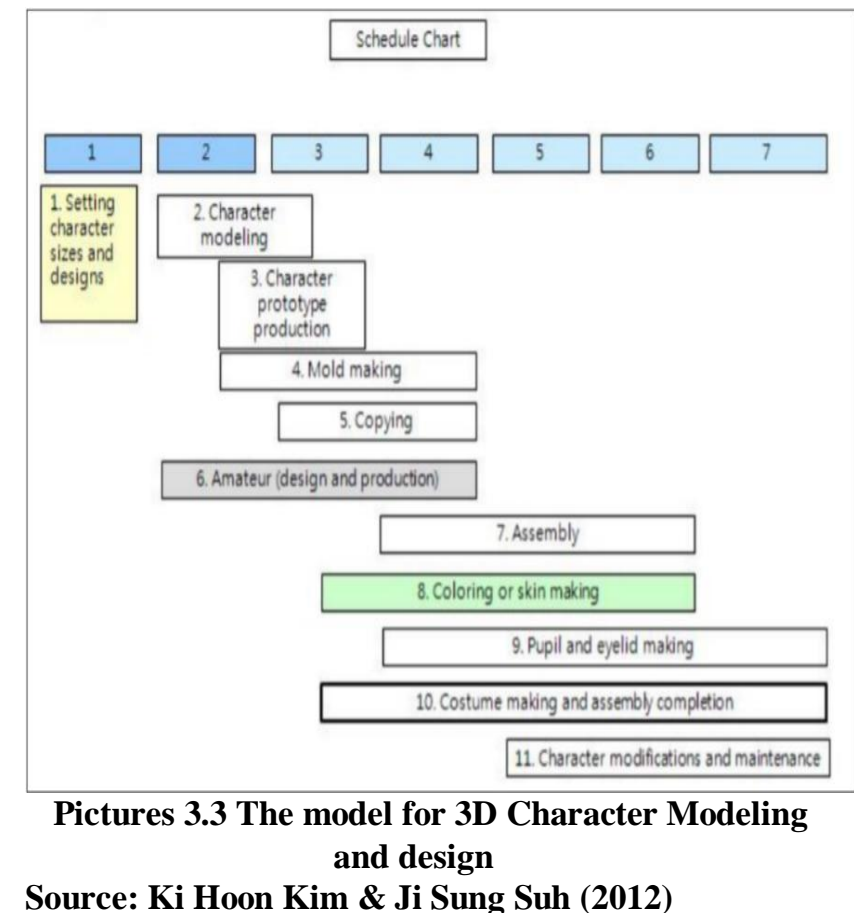

Refers to picture 3.3, there are 7 step in this model. Starting from designing the character the last step is character modification and maintenance. The step to design a character are setting the character size and design. This is including to design it in 2D sketches and using 2D software. There are very importance that to design the character first before modeling it into 3D. for the second step, there are a bunch of step to developing it, character modeling, making the character prototype and models, mold making, and copying. There are the important step are requed in the 3D modeling and model making.

the process of $3 \mathrm{D}$ character modeling of the character for the main character (a superhero) are very importance to give the heroic touch to a character. According to (Faryna Mohd Khalis, 2016) A superhero in comics or magazines are incredibly illustrated as good looking, extraordinarily strong, rare, with a perfect figure.

The costume and the character outfit also playing the biggest role in character design and modeling. According to (Ishak, 2014) which refers to Ki Hoon Kim \& Ji Sung Suh that trying to specified that costume making process for animation character's appearance is not the same with the costume making process for regular wear in stop motion animation character's design. The Character costume

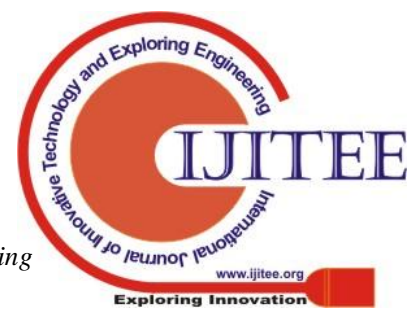


making process includes:-

Confirming image sketches

$\square$ Checking sizes of each part

Analyses on join movements and body types

$\checkmark$ Color chart check

$\square$ Selecting Material (Fabric)

Material screen check (Tint and texture)

$\square$ Rough pattern making

$\square$ Fitting

Modified pattern making

$\square$ Wearing
I divided my research source into two section, primary source and secondary source. For the primary sectors, I do a movie revision like Upin \& Ipin series and Boboiboy Series, for the movie revision. The movie revision is the best method to review the character design and the important of character design in a movies. The next source is Official You Tube Channel. And observation. I also interview the lecture for getting the information about character designing and modeling.

For the secondary source, I likely to use University thesis, Publish Journals, and books.

\subsection{Method Research}

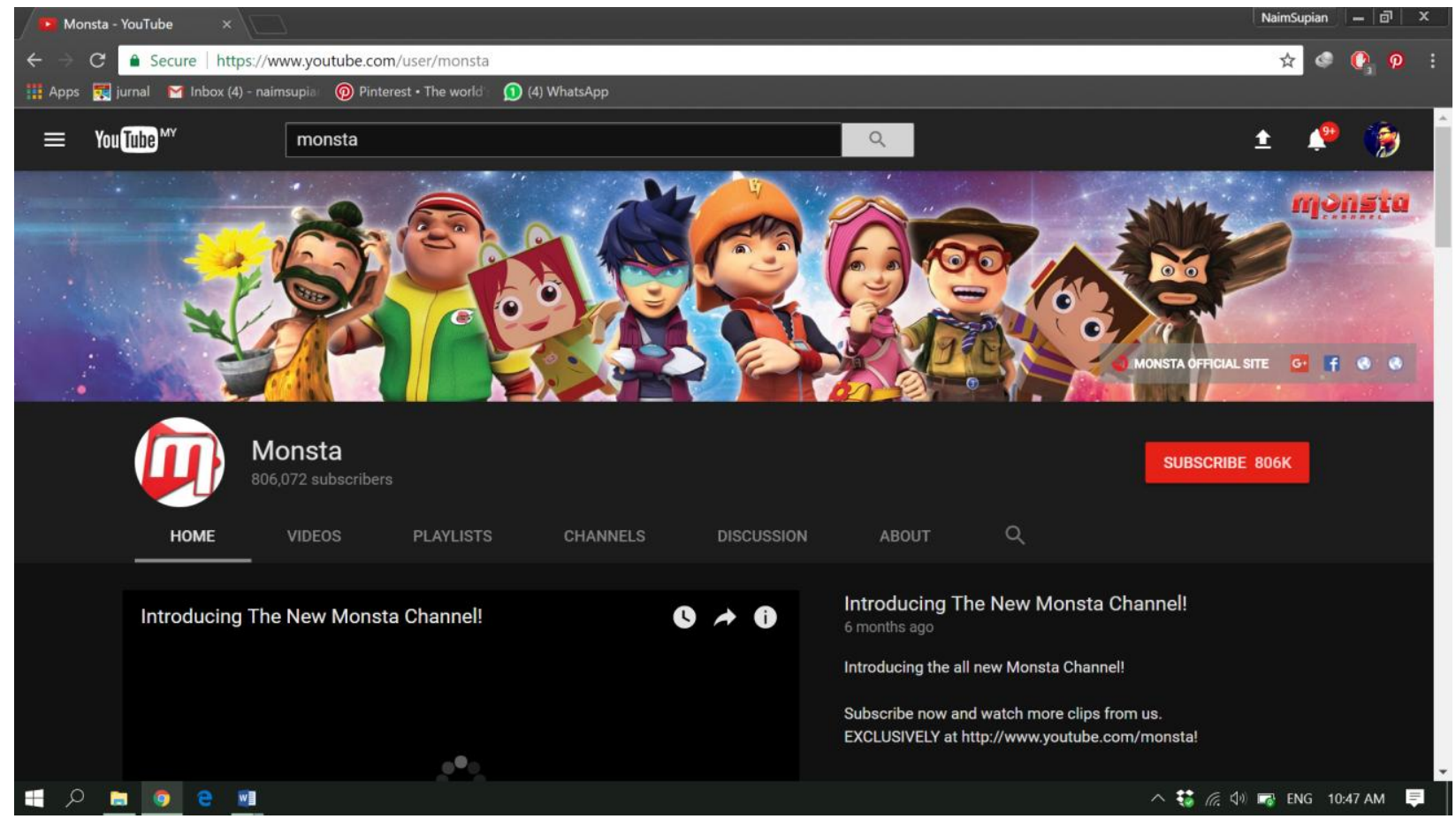

Picture 3.4 The Monsta Youtube Webpage. (Primary Source)

Source Monsta, You Tube

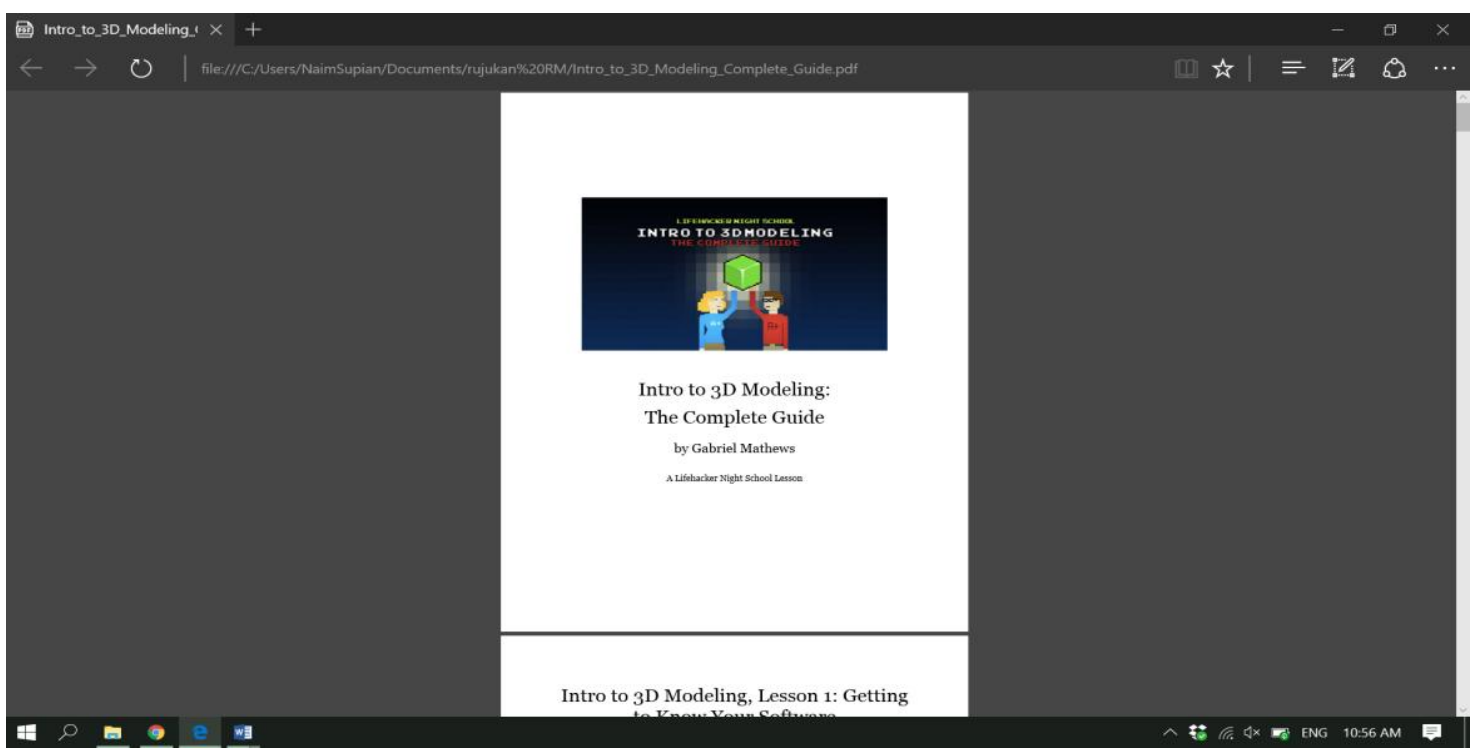

Picture 3.5 The journal of 3D Modeling.

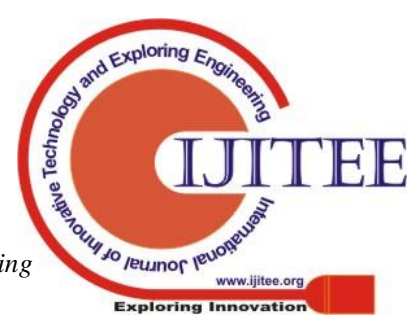




\subsection{Conclusion and Discussion.}

As the conclusion, the character design and modeling in $3 \mathrm{D}$ are very important to give an animation become alive. The character design also give the strength to a movie making the movie more give an impact to the audience. The most important, the value of esthetic of culture should affect the designing the character. The character not only rigid to the human form, but the character also can be anything, according object can be a character for an animation.

The influences of Japanese and Western are giving some impact for the animators in Malaysia to create thear own models and characters. For showing the hero-look alike character, Malaysian animators using western styles which taking reference from cloth and the appearal. For the physical and character movement, the Malaysian animators taking Japanese fluent as references.

\section{BIBLIOGRAPHY}

1 Bailey, S. (April 15, 2013). Building and Using a Character in 3D Space . 19.

2 Bane, A. (2012). 3D Animation Essentials. Indianapolis, Indiana: John Wiley \& Sons.

3 Faryna Mohd Khalis, N. M. (2016). The Sense fo Local Identity Characteristic in Malaysian Animation . 12.

4 Isa, S. S. (2012). Development Issues for the Creative Economy In Malaysia. 203.

5 Ishak, M. A. (2014). Understanding Malaysian Animation Characteristic : A Structurlist -Semotic Analysis On Malaysian Animation Series . 14.

6 Monsta (Director). (2016). Disebalik Tabir : Boboiboy The Movie [Motion Picture].

7 Plata, B. M. (2013). 3D Modeling Optimization for Multimedia Production . 47.

8 Vaughan, W. (2012). Digital Modeling . Berkeley, CA: Pearson Education.

9 Weh-Cheih Chang, W.-M. J. (2015). Streamlined Workflow for 3D Modeling with Animated Characters. 7.

10 Wise R, S. J. (2000). Multimedia : A Critical Introduction. London: Tay-lor \& Francis Group .

11 Xi-Dao LUAN, Y.-X. X.-D. (2008). Research and Develpment od 3D Modeling. 5. 